\title{
CARTAS CONTRA LAS OBRAS DE SANTA TERESA DE JESÚS ${ }^{1}$
}

\author{
Rocío PÉREZ-GIRONDA \\ Universidad Autónoma de Madrid \\ rocio.perezg@estudiante.uam.es
}

\section{INTRODUCCIÓN}

uando nos acercamos a una autora como santa Teresa de Jesús lo primero a lo que se hace referencia es al gran número de conventos que fundó por todo el territorio español, así como a los éxtasis que han acabado inmortalizados en obras de distintos campos artísticos y sus libros. Tanto el tema religioso como la escritura son dos elementos muy relacionados entre sí y, en este caso, el segundo acabó siendo una consecuencia del primero, ya fuera para narrar su propia vida o para contar sus fundaciones o experiencias místicas. Debido al contenido que podemos encontrar en sus textos, hubo varias personas que, incluso después de su muerte cuando fray Luis de León decidió crear una edición de sus obras, escribieron al Santo Oficio para que prohibieran estos escritos por ser una doctrina engañosa.

Vamos a tratar de mostrar en esta investigación cuáles fueron las acusaciones que se hicieron en contra de los textos teresianos cuando, después de su fallecimiento, se publicaron sus obras en una edición conjunta. Intentamos ver de esta manera si son correctas o hay algo más detrás de ellas. No todas las cartas dirigidas al Santo Oficio tenían como fin la prohibición, también podemos encontrar defensores de sus prácticas y, por lo tanto, de su obra.

Para poder cumplir con el objetivo marcado, haremos un acercamiento a las cartas en las que se producen las denuncias, haciendo hincapié en las menciones al diablo que hay en ellas, ya que uno de los principales cometidos de la Inquisición era evitar que la herejía se propagase. Los autores que más destacan como acusadores

\footnotetext{
1 Este artículo se ha desarrollado dentro del grupo de investigación «Mentalidades mágicas y discursos antisupersticiosos (siglos XVI, XVII y XVIII)», grupo consolidado por la Universidad Autónoma de Madrid.
}

Edad de Oro, XXXVIII (2019), pp. 89-102, ISSN: 0212-0429 - ISSNe: 2605-3314 
son: fray Alonso de la Fuente, que es el primero que realiza la crítica y es de los más insistentes; fray Juan de Lorenzana, que es el encargado oficial de realizar la calificación de las obras teresianas; y fray Juan de Orellana, que ratificaría la censura realizada por el autor anterior. En cuanto a las defensas, es importante mencionar una carta anónima enviada al Santo Oficio donde se especifica de forma clara por qué los textos no son dañinos como tratan de hacer pensar los otros religiosos.

\section{Procesos contra santa Teresa de Jesús}

Aunque en estas páginas vamos a centrarnos en las acusaciones que recibieron las obras de santa Teresa de Jesús cuando se publicaron después de su muerte, también es importante saber qué sucedió antes, pues no era la primera vez que esta autora cayó en manos de la Inquisición.

La función principal por la que el Santo Oficio se fundó en España fue la lucha contra la herejía en el reino, siendo una de sus actividades el examen de la producción literaria. Este control era mayor cuando los textos que se creaban contenían temas religiosos porque podían enseñar doctrinas heréticas que iban en contra de lo establecido, pudiendo llegar a gente no experta. Era un problema que querían solventar y por ello «la censura fue [...] uno más de los instrumentos con que se trató de hacer frente a la expansión de la herejía» (Alcalá 1984: 270). Para que se produjera la censura de una obra había dos posibilidades: la delación, una «denuncia puesta por alguna persona y cuyo destinatario era la Inquisición» (1984: 272), o la interceptación en los controles realizados «desde que salía de las manos del autor hasta que llegaba hasta las del lector» (1984: 275). Las obras de santa Teresa de Jesús nunca estuvieron prohibidas por la institución religiosa, pero sí que sufrieron denuncias.

A todo esto, se suma que es un momento histórico en el que aparecen corrientes religiosas adversas al catolicismo dominante. Entre ellas destacan los protestantes, nacidos de la Reforma y liderados por Lutero; y los alumbrados, que no creen en las escrituras y se dejan llevar por los designios de Dios. Es durante esta época cuando encontramos a la autora, que fue acusada de enseñar una doctrina similar, teniendo como consecuencia una vigilancia constante:

La vigilancia que la Inquisición ejerció sobre la Madre Teresa (1515-1582) fue constante desde que supo que había redactado una Vida en que contaba sus muy especiales experiencias, pero ya antes sospechaba de ella por su continuo contacto con gran parte de las personalidades y ambientes religiosos (Alcalá 2001: 57).

Como menciona Alcalá en este fragmento, que la escritora estuviera en contacto con grandes personalidades religiosas y que realizara una obra autobiográfica 
donde narraba todas sus experiencias místicas, la convirtieron en un blanco perfecto para el control inquisitorial. Por lo tanto, podemos decir que «los procesos contra la Madre Teresa son [...] signo de la época y exigencias del ambiente» (Llamas 1972: 27).

Algunos de estos enfrentamientos con la Inquisición ocurrieron cuando la autora todavía estaba viva ${ }^{2}$ y otros después de su fallecimiento, cuando las obras fueron editadas y publicadas. En este apartado trataremos de forma breve lo que ocurrió en los primeros casos, y en el siguiente haremos un análisis de las cartas que contienen las acusaciones contra sus escritos, centrándonos en las menciones que se hacen de su posible acercamiento a Satanás.

La primera vez que vemos mencionado el nombre de Teresa de Jesús en un proceso inquisitorial es en Córdoba. Esto se debe a que tiene contacto con uno de los acusados por pertenecer a los alumbrados, el doctor de Carleval. En esta ocasión es denunciada ella y no sus libros, como sucederá en otras ocasiones, aunque en estos momentos ya había elaborado su obra autobiográfica, Vida, y había empezado a moverse por círculos religiosos reducidos.

El siguiente proceso sucedió en Valladolid y, en esta ocasión, el escrito mencionado parece ser el eje central, porque «podía encerrar graves inconvenientes [...] y ocasionar un perjuicio para la vida espiritual de aquella época turbulenta» (Llamas 1972: 44), por lo que el documento es solicitado para su revisión. Además de en esta ciudad, también es requerido por el Consejo Superior de Madrid para el mismo cometido. La obra había seguido moviéndose, e incluso se habían realizado diferentes copias, aunque la mayoría incompletas y que no partían del manuscrito original. En la segunda ciudad el padre Báñez, antiguo confesor de la monja carmelita, fue designado para llevar a cabo la revisión. Tras realizarla, aconseja que el texto sea retenido por el Santo Oficio, pero no prohibido, hasta después de la muerte de la autora. Esta recomendación es aceptada, y hasta 1586 no será devuelto a la Orden fundada por santa Teresa de Jesús.

Vida es el libro más revisado y con el que más cuidado tuvo la Inquisición, ya que, a pesar de seguir creando escritos, nunca gozaron de tanta repercusión. Quizá esto se deba a que en la obra menciona en numerosas ocasiones al diablo y aparecen sus perpetuas dudas de si los favores que está recibiendo son producto de Dios o del Maligno. En los textos que comentaremos más adelante la mayoría de los ejemplos usados para confirmar que la doctrina de la religiosa es herética son de esta obra.

2 Todos estos procesos pueden consultarse de forma mucho más extensa y con un análisis pormenorizado en la obra de Enrique Llamas, Santa Teresa de Jesús y la Inquisición española. En este libro se realiza un estudio tanto de las acusaciones como del contexto en el que se formaron, aportando todos los detalles necesarios. 
El tercer y último proceso que vamos a comentar sucedió en Sevilla, donde fue acusada en dos ocasiones. La primera por cómo vivían tanto ella como sus monjas; se lo tomó como «una aprobación de su vida y de sus enseñanzas sobre la oración mental, alma de sus monasterios y de su reforma carmeliana» (Llamas 1972: 125); y la segunda por mantener supuestas relaciones ilícitas con otro miembro de la Iglesia, lo que desencadenó que contestara duramente a las acusaciones.

De todos estos enfrentamientos siempre salió absuelta. La única pena que recibió fue la retención de su obra, pero esta fue devuelta más tarde y acabó siendo una pieza muy importante para las recriminaciones posteriores.

\section{Acusaciones Contra la obra teresiana (1589-1593)}

En el año 1588, fray Luis de León decidió hacer una edición donde apareciesen los textos de santa Teresa de Jesús. Entre ellos destacan Camino a la perfección, Moradas y Vida. Esta última había sido liberada del poder inquisitorial apenas un par de años antes y las tres contenían temas de carácter religioso. Fue una publicación aceptada, pero «aparecieron muy pronto voces de acusación contra su doctrina; recelos de su vida [...]; quejas de su popularidad; delaciones al tribunal de la Inquisición, pidiendo la revisión de los libros, su corrección, e incluso que fuera prohibida su lectura» (Sagrado Corazón 1982: 535). Los nombres que destacan en este enfrentamiento contra las obras teresianas son Alonso de la Fuente, el padre Orellana y Juan de Lorenzana. Los tres eran dominicos y llama la atención que no quisieran las obras de la santa, cuando en dicha Orden tenía muchos defensores tanto de su vida como de su doctrina. Estos religiosos creían que existía una sospechosa vinculación entre la autora mística y el demonio.

No solo encontramos acusadores; también hay defensores que al leer dichas reclamaciones decidieron rebatirlas. Estos son Antonio de Quevedo y otra aportación anónima. El primero conocía las acusaciones previas y el segundo había tenido acceso a la primera que realizó De la Fuente, ya que sigue su misma estructura y es una clara contestación a lo que el dominico escribió. Querían mostrar que, en realidad, esta mujer sí que estuvo en gracia de Dios, a pesar de las continuas tentaciones demoniacas a las que se veía sometida, superándolas con éxito y mostrándoselas al mundo en sus obras.

Fray Alonso de la Fuente es el más insistente y el que primero alza la voz en contra de la obra teresiana. Presenta un total de cinco memoriales al Santo Oficio, de los cuales se conservan cuatro en el Archivo Histórico Nacional de Madrid,

3 Las cartas junto a los memoriales que se conservan están recogidos de la siguiente manera en el Archivo Histórico Nacional: el que hace referencia al análisis del cuarto grado de oración está 
para censurar los textos de esta escritora y evitar que dicha doctrina se extendiera. Para ello, la analiza centrándose en los grados de oración y las diferencias entre la vocal y la mental. Según este religioso, dicha doctrina era errónea y herética, estaba próxima a los alumbrados, grupo contra el que luchó durante toda su vida, y al demonio. También es importante remarcar que, a pesar de su mucha insistencia, la Inquisición parecía no prestar demasiada importancia a las palabras de este autor. Podemos observarlo por oraciones como: «no encuentro respuesta de mis cartas ni que se han recibido y han puesto en cuidado, si mis trabajos se han recibido con la gracia y piedad que mi buen celo merece» $\mathrm{o}$ «ni se si se han recibido y mero me avisen si han llegado por allá» (AHN, Inq, leg. 4.425, exp. 22) 4

Junto al primer memorial que realiza encontramos una carta dirigida al Consejo en 1589. En ella expone su opinión sobre las obras teresianas de forma general y qué se debería hacer con ellas: una revisión de los textos por teólogos expertos y prohibirlos. Para él todo lo que aparece narrado es herejía y acusa directamente a la monja de estar siendo engañada por Lucifer y enseñar una doctrina errónea:

El autor de dicho libro lo vende y encomienda por doctrina revelada de Dios e inspirada por el Espíritu Santo, que si en efecto fue la monja como suena el título de él, es negocio [...] y cosa enseñada por el ángel porque excede la capacidad de mujer. Mas no fue posible ser ángel bueno sino ángel malo y el mismo que engañó a Mahoma y a Lutero y a los demás herejíacas [...]. El milagro que se dice de la monja Teresa de Jesús, que está hoy entera e incorrupta, es negocio fabuloso, o prestigio de Satanás o invención de herejes (AHN, Inq, leg. 4.425, exp. 22).

Por lo que observamos, para él todo lo que ha escrito la autora ha sido obra del diablo y no una revelación de Dios, porque «no hay en ellos cosa que se escape de mentira o fabula o error o herejía o secta o sueño diabólico» (AHN, Inq, leg. 4.425, exp. 22). Esta idea aparece repetida en más ocasiones a lo largo del resto de los memoriales; por ejemplo, cuando habla del cuarto grado de oración, al final, nos vuelve a decir que «todo lo demás que enseña» es «herética y secta infernal y siendo que le enseñó el demonio» (AHN, Inq, leg. 2.706, n. ${ }^{\circ} 27$ ).

Santa Teresa de Jesús siempre tuvo dudas de si los regalos que recibía eran algo bueno o venían del demonio, aunque al final estas dudas se disiparan teniendo claro que su benefactor era Dios. Para este autor no es así, «confunde las obras de Dios con las de Satanás» (AHN, Inq, leg. 4.425, exp. 22). Con el fin de demostrarlo, se centra en varios puntos a lo largo de sus escritos y realiza una crítica completa.

en Inquisición, leg. 2.706, n. ${ }^{\circ}$ 27; y los tres restantes aparecen en Inquisición, leg. 4.425, exp. 22, aunque también lo encontramos en microfilme, neg. 3.052.

4 Tanto este texto y todos los que aparecen a continuación han sido actualizados ortográficamente para una mayor comprensión. 
Analiza la unión con Dios, los medios que usa y los efectos que tiene, que es uno de los elementos clave en la doctrina teresiana. En todos estos puntos se menciona al diablo como el verdadero responsable de lo que vive la autora mística. Podemos encontrarlo en tres de los memoriales: en el primero, que es donde califica de forma general la doctrina; en el que trata el tercer grado de oración; $y$, en el último, cuando habla la oración mental y la vocal.

En palabras del religioso, esta mujer defiende que Dios está en nuestro interior y hay que llegar a él mediante la contemplación y no a través de la mortificación del cuerpo y de las pasiones. De esta manera estaría potenciando la utilización de la oración mental, pero se «les dice que no hagan tal género de oración porque es peligros» y es «obra manifiesta de Satanás» (AHN, Inq, leg. 4.425, exp. 22). Entran en un estado que «infunde Satanás» para hacerles creer que las revelaciones que viven son de Dios cuando en realidad son producidas por el Maligno y en ellas «les muestra [...] el mundo y misterio de la eternidad y la esencia divina» (AHN, Inq, leg. 4.425, exp. 22). Para este autor, entrar en ese estado es abrir «la puerta a Satanás» para que se acerque más fácilmente y engañe. Es una doctrina que también aparece en los alumbrados, por lo que estaría dentro de las prácticas heréticas que había que erradicar. Además, la escritora defiende que cualquiera puede llegar al estado de unión, ya que si el que lo alcanza lleva una vida pecaminosa, el regalo será mayor. Esto es calificado como negativo por el fraile porque es un nivel que tendría que estar reservado a las personas espirituales.

En cuanto a los efectos que produce la unión con Dios, se ven claras diferencias a cuando están producidos por Satán. Cuando es con el segundo se describe como «dura, violenta [...] y llena de temor y sobresalto», mientras que si es con el Señor es «dulce, sublime [...] llena de seguridad» (AHN, Inq, leg. 4.425, exp. 22). En los textos de santa Teresa de Jesús se muestran temores y dudas, por lo que el religioso califica estas uniones de heréticas.

Es importante remarcar que, aunque sí es cierto que las revelaciones eran un elemento propio de la Iglesia, estas no se repetían con la asiduidad que dice la santa: «Los raptos y las elevaciones y efectos semejantes, cuando vienen por orden de Dios son rarísimos y de mil a mil años; y cuando se hallaren de ley común y en tales supuestos [...] es conocida de Satanás» (AHN, Inq, leg. 4.425, exp. 22). Ella los describe como algo común a lo largo de su vida, por lo que iría en contra de lo que De la Fuente considera buena doctrina.

Otro de los posibles puntos de unión entre la monja y el diablo es que la primera no logra encontrar confesor durante mucho tiempo, porque nadie entiende qué le ocurre. Esto aparece narrado en la primera crítica que hace De la Fuente y también podemos encontrarlo en la obra autobiográfica de la mística. Algunos de estos posibles confesores o «siervos de Dios», como los cataloga el fraile dominico, ya habían acusado a esta mujer de que sus mercedes eran diabólicas: «la tuvieron 
por demonio en consultas graves, confirmándose la sospecha del mal espíritu [...] y $[\ldots]$ determinase en particular el espíritu fue el demonio y obra suya» (AHN, Inq, leg. 4.425, exp. 22). Que estos religiosos pensasen así tiene que ver con lo que ella narra en sus textos y que este autor comenta en las redacciones enviadas a la institución inquisitorial.

Por último, hay que mencionar que la relación entre el género femenino y el señor de los infiernos está muy presente en estas acusaciones. Esto era algo común en la época, se pone a la mujer como elemento predispuesto al engaño del demonio tomando como primera referencia a Eva y la expulsión del paraíso. Observamos que esta idea aparece en los memoriales del dominico cuando dice: «más sabían estos hombres doctos y graduados que no una mujer; mas no es cosa nueva, las mujeres de vida y doctrina errada engañan a los hombres sabios y eminentes porque una engañó en orígenes» (AHN, Inq, leg. 4.425, exp. 22). Santa Teresa de Jesús, a través de sus obras, estaría mintiendo con su doctrina, premisa principal de todas las críticas, a los que se acerquen a ellas. En la calificación sobre el cuarto grado de la oración vuelve a mencionarse este tema cuando se dice que las féminas son las más afectadas por el rapto demoniaco, quedando en un estado inmóvil, y a las que cataloga de súcubas (AHN, Inq, leg. 2.706, n. ${ }^{\circ} 27$ ). Por lo tanto, si este autor ya estaba convencido de que las prácticas de la escritora mística eran heréticas, y que sus arrobamientos eran producidos por el demonio, el hecho de ser mujer parece darle más razones para acusarla y exigir que sus libros sean prohibidos.

A pesar de la insistencia de fray Alonso de la Fuente, no es el encargado oficial para realizar la censura de los libros. Después de él, aparecen otros dos dominicos para hacer acusaciones en contra de las obras y la doctrina teresianas. Estos son fray Juan de Orellana y fray Juan de Lorenzana. Cuando nos acercamos a las cartas enviadas por ellos, comprobamos que el Consejo puso a cargo de la censura a Lorenzana, y Orellana lo deja claro diciendo: «Habiendo visto mandato del Consejo Real de la santa y general Inquisición, la censura que presta fray Juan de Lorenzana hizo en los libros de la madre Teresa de Jesús» (AHN, Inq, leg. 4.425, exp. 22). Aun así, esta orden se produce después de que De la Fuente realizara sus acusaciones y que Lorenzana supiera de ellas: «con cinco memoriales que se han dado en aquel Santo Oficio en razón de los libros que quieren expurgar» (AHN, Inq, leg. 4.425, exp. 22).

Antes de que Lorenzana comience con dicha censura, Orellana envía una carta al Consejo donde, de manera breve, expone la doctrina de santa Teresa de Jesús y pide que las obras sean prohibidas por contener abundantes errores doctrinales. A pesar de su corta extensión, vemos una de las ideas comentadas ya en los textos de De la Fuente, y es que la mujer es mucho más fácil de engañar por doctrinas heréticas y caer en las garras del diablo. Lo expresa de la siguiente manera: «esta 
doctrina para que, a muchos, señaladamente mujeres, los engañe el diablo transfigurado en ángel de luz» (AHN, Inq, leg. 4.425, exp. 22).

En la calificación realizada por Lorenzana llaman la atención varias aspectos. Lo primero es que deja claro que él solo va a juzgar el contenido de los libros de la autora carmelita porque «no quiero ni es mi intención poner mácula en Teresa de Jesús, antes la tengo por virtud y buena mujer» (AHN, Inq, leg. 4.425, exp. 22). Para él, ella vivía dentro de los parámetros establecidos, pero su obra y doctrina no. Lorenzana la conoció en persona durante la fundación de un convento en Valladolid, por lo que, al principio, tenía las obras de la religiosa en gran estima, pero esto cambia cuando cruza por su vida Juan de Orellana (Sagrado Corazón 1982: 556).

Lo segundo tiene relación con las menciones al demonio que aparecen en su censura. Observamos que, para él, como ya sucedía con De la Fuente, en los libros hay «algunas cosas $[\ldots]$ por instinto divino $[\ldots]$ y otras de parte del diablo» porque «tantas veces se engañó pensando que le hablaba Dios y le hablaba el diablo» (AHN, Inq, leg. 4.425, exp. 22). También defiende que ha sido engañada por Satán, pero el tono con el que lo expresa no es tan severo como el del anterior autor. Esta idea la vemos en varias ocasiones a lo largo de la calificación que envía al Santo Oficio.

Hay un menor número de llamamientos al demonio que en los textos del anterior dominico, ya que este autor analiza los errores teológicos que contienen las obras teresianas, centrados en el proceso de unión entre alma y Dios y todo lo que sucede en él. Podemos ver muchas referencias a textos bíblicos y a documentos que le sirven de justificación a sus correcciones, la mayoría de ellos en latín. Esto demuestra que era un religioso culto, siendo por ello un candidato perfecto para la corrección de los escritos de la santa.

Lo último que vamos a mencionar relacionado con este autor aparece al final de su censura, donde expone qué es lo que quiere conseguir con ella y los motivos. Lo que pide es que «se manden vedar estos libros y tratados de Teresa de Jesús» porque «hacen gran daño $[\ldots]$ porque andan por manos de señoras y beatas y otra mucha gente, y los de su Orden, monjas y frailes descalzos, tienen estos libros por oráculo y como constituciones y modo de vivir de su Orden y así deben de estar llenos de estos errores» (AHN, Inq, leg. 4.425, exp. 22). Las obras teresianas se extendieron rápidamente, y lo que estos miembros de la Iglesia querían evitar es que la gente no experta en el tema cayera en las herejías que supuestamente contenían estos textos, por eso había que impedir su difusión.

Después de esta censura, Orellana vuelve a hacer otra apelación a la prohibición de las obras de santa Teresa de Jesús y, como él mismo expone en dicho documento, va a tener como base para su crítica la calificación de Lorenzana y los textos de la autora mística. 
Ninguno de los autores mencionados cree que Dios haya revelado la doctrina a esta mujer. Orellana, para hablar de este asunto, hace una comparación entre los profetas de Dios y los del demonio diciendo que «el profeta de Dios siempre dice verdad $[\ldots]$ tiene certidumbre inefable que es de Dios [...] Mas los profetas falsos del demonio [...] alguna vez dicen verdad por engañar después con su mentira» (AHN, Inq, leg. 4.425, exp. 22). Para él, la santa estaría en ese segundo grupo porque, aunque algunas cosas sean ciertas, otras muchas no, partiendo de la base de que ella misma duda de si sus arrobamientos fueron traídos por el bien o por el mal.

Esta idea la vemos también en cuanto a la realización de los milagros pues, según el censor, los que aparecen en las obras «no lo son [...] ninguno hay entre todos ellos que no pueda ser o prestigio del demonio, o verdadero efecto por aplicación de causas naturales ignotas a los hombres, pero muy sabidas por el demonio que a los hombres les parecen milagros no lo siendo» (AHN, Inq, leg. 4.425, exp. 22). No obstante, al avanzar en la lectura del documento de este dominico, observamos que él mismo dice que la religiosa sí que realizó milagros, «pero no fueron hechos en comprobación de la mala doctrina que en sus libros hay» e insta a que la «Santa Inquisición no haga caso de cuantos verdaderos milagros hubiere hecho su autora» (AHN, Inq, leg. 4.425, exp. 22). Por lo tanto, observamos que este autor quiere condenar las obras teresianas, aunque haya ciertos milagros, porque las malas doctrinas expuestas en ellos tendrían mucho más peso.

El resto de las alusiones al demonio que aparecen a lo largo de este texto sirven para ratificar la idea que estamos comentando, que la doctrina teresiana está llena de falsedades y las revelaciones han sido provocadas por el Maligno, por lo que es necesaria la prohibición. Sin embargo, al igual que en Lorenzana, vemos que siente cierto respeto por la autora cuando dice: «como yo creo que le acontecía a la madre Teresa que sin ninguna duda la tengo por engañada del diablo, mas no fue de mención y de propósito engañadora» (AHN, Inq, leg. 4.425, exp. 22). Es decir, ella ha caído en las redes de Satanás, pero su intención no era enseñar esa mala doctrina en sus textos, solo que como lo hace hay que censurarlos.

Poco tiempo después de la calificación realizada por Orellana, Lorenzana vuelve a escribir para que todos los documentos lleguen a la Inquisición y pide de nuevo que los libros de la autora mística sean prohibidos.

Hubo otra acusación, pero este texto no se ha conservado, por lo que no podemos ver cuáles eran los argumentos que empleó su autor. Fue realizado por Antonio de Sosa y tenemos pruebas de que el papel existió porque aparece en una carta enviada al Santo Oficio: «Vuestra merced mandara lo que fuera seguro el padre fray Antonio de Sosa [...] ha presentado en este Santo Oficio ciertas advertencias en cuatro hojas de papel que esta anotado de un libro de la madre Teresa de Jesús» (AHN, Inq, leg. 4.425, exp. 22). Pero no sabemos nada más. 
Aun así, no todo fueron acusaciones, también tenemos constancia de dos alegaciones a favor de las obras de la autora mística y su forma de vida. La primera estaría realizada de forma anónima y sin fecha, pero sabemos, por su contenido, que sería posterior la primera carta enviada por fray Alonso de la Fuente, porque sigue su misma estructura y va contestando a todas las recriminaciones. Esto demostraría que los memoriales que el dominico envió estaban siendo recibidos en el Santo Oficio, aunque él no estuviera seguro.

En esta primera defensa se mencionan los procesos en los que se vio involucrada la monja carmelita. Deja claro que «aunque en su vida fue harta calumniada de muchos, nunca se halló contra ella en su vida y costumbre mácula». Además, si tan mala fue su doctrina, le extraña «que en tanto tiempo no se hubiera descubierto» (AHN, Inq, leg. 4.425, exp. 22). En el resto de la carta va justificando uno a uno todos esos supuestos errores que cometía la autora y que hacían que estuviera más próxima a Lucifer que a Dios. Un ejemplo de esto lo vemos cuando De la Fuente critica que la religiosa no encuentra confesor porque nadie entiende por lo que pasa y él lo asocia al Maligno. El defensor lo explica diciendo que los medios que usó Dios fueron «tan extraños [...] con visiones y revelaciones tan singulares» (AHN, Inq, leg. 4.425, exp. 22) que era normal que no lograsen entenderla. Esta estructura se va repitiendo a lo largo de toda la defensa anónima.

Un proceso bastante similar sigue la segunda, que en esta ocasión sí que aparece fechada y firmada por su autor, Antonio de Quevedo. Pero mientras que la anterior estaba enfocada en rebatir las opiniones expuestas en el primer memorial de De la Fuente, por las referencias que encontramos en este, vemos que había tenido acceso a más acusaciones. Va comentando detalladamente la doctrina expuesta en los libros de santa Teresa de Jesús, como, por ejemplo, los grados de oración y cómo se lleva a cabo la unión entre ella y Dios. Además, ejemplifica todo con referencias sacadas de santos o personajes destacados de la Iglesia para justificar su defensa (AHN, Inq, leg. 4.425, exp. 22). La conclusión que saca de este análisis es que lo que defiende la escritora es correcto y verdadero, considerándolo un «rico tesoro que el Señor ha legado a su Iglesia» (Sagrado Corazón 1982: 554).

\section{ConClusión}

La Inquisición siempre vigiló a la autora mística. Durante su vida estuvo varias veces acusada y en diferentes ciudades, ya fuera por su forma de vida o por sus obras. Tras uno de esos procesos y la recomendación de uno de sus confesores, su texto más insigne y donde hay un mayor contenido místico, Vida, queda guardado en las arcas inquisitoriales. Esta obra quedaría libre tras su muerte y es el momento en el que aparece la edición de fray Luis de León, volviendo el revuelo $\mathrm{y}$ nuevas acusaciones. 
Tenemos muchos más documentos en contra de santa Teresa de Jesús que defensas en este proceso. Esto es bastante llamativo ya que, a pesar de ello, las obras no fueron censuradas, lo que nos hace pensar que posiblemente las alegaciones a favor tuvieran un gran impacto, o que alguien protegía a la autora en los círculos más internos de la Inquisición. Es algo que no podemos confirmar debido a que no se han conservado más archivos acerca de las acusaciones.

Después de analizar los textos de denuncia, observamos que el diablo aparece citado en todos ellos como un elemento presente en la doctrina teresiana, siendo el motivo principal por el que esas obras tenían que ser prohibidas para que no se extendiesen. Para los acusadores, lo narrado por la autora no fue revelación divina sino demoniaca, por lo que todo lo que vivió y cuenta no son más que engaños. Además, como hemos podido ver por algunas de las menciones al demonio, el hecho de ser mujer también era un motivo por el que era más probable que estuviera unida al ser de los infiernos. Todo esto lo corroboran aportando diferentes ejemplos de por qué es contrario a lo establecido, haciendo una crítica exhaustiva. Por lo tanto, queda claro que tanto en las obras de santa Teresa de Jesús como en las acusaciones que recibe, el diablo es un elemento destacado y por ello es digno de mencionar. Pero también encontramos defensores que, con sus respectivas justificaciones, tratan de rebatir esas palabras. Es importante remarcar que hubo autores que, aunque catalogaron con dureza la doctrina mística de esta autora, no se involucraron en su manera de vivir, teniendo un gran respeto por su trayectoria religiosa.

Los dos grupos, acusación y defensa, aportan argumentos justificados, pero parece que el segundo acaba alzándose con la victoria porque, aunque parecía claro que la santa estaba condenada a terminar junto a sus obras en los archivos ocultos de la Inquisición, no es así y hoy podemos disfrutar de sus palabras. 


\section{BIBLIOGRAFÍA}

Alcalá, Ángel (2001). Literatura y ciencia ante la Inquisición española. Madrid: Ediciones Laberinto.

AlCALÁ, Ángel et alii (1984). Inquisición española y mentalidad inquisitorial. Barcelona: Ariel.

Álvarez, Tomás (1977). «Santa Teresa de Jesús y la Inquisición española. Nuevas aclaraciones». Teresianum, 28, 2, pp. 338-350.

Archivo Histórico Nacional (AHN - Madrid), Inq., leg. 2.706, n. ${ }^{\circ} 27$.

Archivo Histórico Nacional (AHN - Madrid), Inq., leg. 3.198, n. ${ }^{\circ} 28$.

Archivo Histórico Nacional (AHN - Madrid), Inq., leg. 4.425, exp. 22/microfilme neg. 3.052 .

BeInART, Haim (1983). Los conversos ante el tribunal de la Inquisición. Barcelona: Riopiedras Ediciones.

CARrera, Elena (2018). «El miedo intersubjetivo en la autobiografía de Teresa de Ávila». Studia Histórica: historia moderna, 40, 2, pp. 63-111.

Contreras, Jaime (1997). Historia de la Inquisición española (1478-1834). Madrid: Arco Libros.

Cruz, Anne J. (2016). «Las formas de vida religiosa femenina en la época de Teresa de Jesús y Catalina de Cardona». eHumanista, 33, pp. 246-265.

Fernández de Bethencourt, F. (1911). «Los parientes de Santa Teresa de Jesús». Boletín de la Academia de Historia, I, pp. 216-223.

García de la Concha, Víctor (1978). El arte literario de Santa Teresa. Barcelona: Ariel.

GonzÁlez CAndela, Francisco Javier (2015). «El contraste místico del bien y el mal: la presencia del demonio en la Vida de santa Teresa de Jesús». En Carlos Mata Induráin y Ana Zúñiga Lacruz (coords.), «Venia docendi». Actas del IV Congreso Internacional Jóvenes Investigadores Siglo de Oro (JISO 2014). Pamplona: GRISO, pp. 85-94.

Herranz VelázQuez, Fernando (2014). «Nuevas aportaciones al debate historiográfico sobre el linaje de santa Teresa de Jesús». En Ernesto Cutillas Orgilés (coord.), Nuevas aportaciones en la investigación en las humanidades. Alicante: Universidad de Alicante, pp. 107-114.

Llamas Martínez, Enrique (1972). Santa Teresa de Jesús y la Inquisición española. Madrid: Bibliotheca Theologica Hispana, s. 1, t. 6.

MÁrquez, Antonio (1980). Literatura e Inquisición en España 1478-1834. Madrid: Taurus. Martínez Millán, José (2007). La Inquisición española. Madrid: Alianza.

Pérez García, Rafael M. (2018). «Francisco de Osuna y Santa Teresa de Jesús. Algunas notas sobre la historia de la mística cristiana en la España del siglo XVI». eHumanista/Conversos, 6, pp. 159-177.

PÉREZ, Joseph (2003). Breve historia de la Inquisición española. Barcelona: Crítica.

Rodríguez, Isaías (1972). Santa Teresa de Jesús y la espiritualidad española. Madrid: Bibliotheca Theologica Hispana, s. 1, t. 7. 
SAgrado Corazón, Enrique del (1982). «Santa Teresa ante de la Inquisición española». Teresianum, 13, 1, pp. 518-565.

SAInz Rodríguez, Pedro (1984). Introducción a la Historia de la Literatura Mística en España. Madrid: Espasa-Calpe.

TAusiet, María y James S. Amelang (eds.) (2004). El diablo en la Edad Moderna. Madrid: Marcial Pons.

Teresa de Jesús, santa (1967). Obras completas. Efren de la Madre de Dios y Otger Steggink (ed.). Madrid: Biblioteca de Autores Cristianos.

VV.AA. (1987). Inquisición española. Nuevas aproximaciones. Madrid: Centro de Estudios Inquisitoriales.

Zamora Calvo, María Jesús (2016). Artes maleficorum. Brujas, magos y demonios en el Siglo de Oro. Barcelona: Calambur Editorial.

Recibido: $24 / 08 / 2019$

Aceptado: 19/09/2019 


\section{Cartas contra las obras de santa Teresa de Jesús}

Resumen: La Inquisición estuvo muy presente durante el Siglo de Oro español. Principalmente se dedicó a controlar las obras literarias que se realizaban, sobre todo, las de carácter religioso, para evitar que las malas doctrinas se extendiesen. Una de las autoras que fue denunciada a la institución fue santa Teresa de Jesús. Parte de estas acusaciones se realizaron después de la muerte de la religiosa, cuando sus obras fueron publicadas por fray Luis de León, aunque también hay algunas cartas en las que fue defendida. Son estas acusaciones las que van a ser analizadas en el presente estudio.

Palabras clave: Santa Teresa, Inquisición, diablo, acusación, cartas.

\section{LetTers AGAINST THE WORK OF SANTA TERESA DE Jesús}

AвSTRACt: The Inquisition was very present during the Spanish Golden Age. Among his duties was to control the literary works that were carried out, especially these of a religious nature, to prevent bad doctrines from spreading. One of the authors who was reported to this institution was Santa Teresa de Jesús. Part of these accusations were made after the death of Santa Teresa de Jesús, when her works were published by Fray Luis de León, although there are also some letters in which she was defended. It is these accusations that will be analyzed in the present study.

Keywords: Santa Teresa, Inquisition, devil, accusation, letters. 